Otsu Watanabe $\cdot$ Kyoko Natori $\cdot$ Mayumi Tamari

Yasuhisa Shiomoto $\cdot$ Shuji Kubo $\cdot$ Yusuke Nakamura

\title{
Significantly elevated expression of PF4 (platelet factor 4) and eotaxin in the NOA mouse, a model for atopic dermatitis
}

\begin{abstract}
The NOA (Naruto Research Institute Otsuka Atrichia) mouse, an animal model of allergic or atopic dermatitis, exhibits ulcerative skin lesions associated with accumulation of mast cells and eosinophils, a significantly increased level of serum IgE, and scratching behavior. To investigate genetic contributors to the pathological process of dermatitis in this murine model, we looked for genes that were expressed differently in spleens of NOA mice compared with controls, by means of a differential display method. We cloned and characterized one gene that revealed a significantly higher expression in the NOA mouse than in control strains. Its cDNA consisted of 570 nucleotides, including 315 nucleotides of open reading frame encoding 105 amino acids. The deduced amino acid sequence identified this gene as the murine homologue of rat and human platelet factor (PF) 4s (89\% identity and 64\% identity in 105 amino acids, respectively). PF4 is a heparinbinding protein that is released from $\alpha$-granules of activated platelets and belongs to the family of chemokine molecules that contain a CXC motif. Our results suggested that increased expression of PF4 may play an important role in the etiology of allergic dermatitis.
\end{abstract}

Key words Chemokine - Atopic dermatitis - Differential display method $\cdot$ Model mouse $\cdot$ mRNA expression

O. Watanabe $\cdot$ K. Natori $\cdot$ M. Tamari $\cdot$ Y. Nakamura $(\bowtie)$

Laboratory of Molecular Medicine, Institute of Medical Science,

University of Tokyo, 4-6-1 Shirokanedai, Minato-ku, Tokyo 108-8639, Japan

Tel. 81-3-5449-5372; Fax 81-3-5449-5433

e-mail: yusuke@ims.u-tokyo.ac.jp

Y. Shiomoto $\cdot$ S. Kubo

Naruto Research Institute, Otsuka Pharmaceutical Factory, Inc.,

Tokushima, Japan

\section{Introduction}

Atopic dermatitis, a condition characterized by spotty ulcerative eruptions, itching, and recurrent remission and progression, is one of the most common allergic diseases of humans worldwide. Often, patients and their family members are also affected with bronchial asthma, allergic rhinitis, or conjunctivitis, and tend to have high levels of serum IgE (Hanifin and Rajka 1980). Although the mechanisms underlying these burdensome symptoms are unclear, it is certain that they are related to dysfunction of the immuno-regulatory system. A large number of research groups have been intensively investigating allergic disorders by various genetic and/or molecular biological approaches (Coleman et al. 1997). However, since multiple genetic and environmental factors are at play, studies that rely on human subjects are extremely complicated. Some investigators have implicated the involvement of FceRI $\beta$ on human chromosome 11, and interleukin 4 on chromosome 5, in the pathology of human atopic dermatitis (Cookson et al. 1992; Shirakawa et al. 1994; Marsh et al. 1994; Noguchi et al. 1997), but other reports are contradictory (Hizawa et al. 1992; Kofler et al. 1996). Hence, if an animal model with a disease phenotype similar to human atopic dermatitis is available, genetic analyses will become much easier.

The NOA (Naruto Research Institute Otsuka Atrichia) mouse has ulcerative skin lesions associated with a remarkable histology that features large numbers of mast cells and eosinophils in and around the lesions (Kondo et al.1997). This strain also shows significantly elevated serum IgE levels (Kondo et al.1997). Therefore we have chosen to investigate this mouse as a model for revealing the genes involved in the etiology of atopic dermatitis.

In recent years various cytokines have been implicated in allergic responses. Using spleen tissues, we employed a polymerase chain reaction (PCR)-based technique called differential display (Liang and Pardee 1992) for screening genes that may be expressed differently in NOA mice and control strains. As differential display is designed to isolate 
Fig. 1. Northern-blot analysis of platelet factor 4 (PF4) in the spleens of NOA, C57BL/6J, and BALB/c mice at two different ages. Fragments obtained from differential display were amplified and used as probes. $\beta$-Actin expression served as a quantitative control. W, Weeks

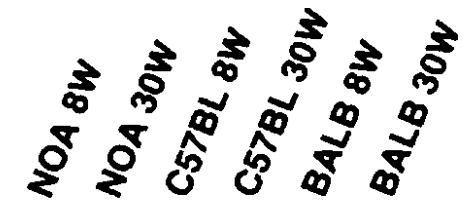

PF4

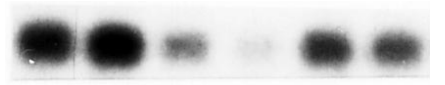

$\beta$-actin

\section{MPF4 \\ RPF4 \\ HPF4 \\ 1 MSVAAVFRGL \\ 1 MSAAAVFRGL \\ 1 MSSAAGFCAS}
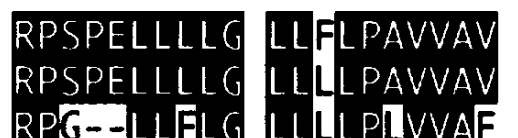

TSASPEESDG

TRASPEESDG

ASAEAEE-DG

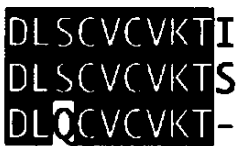

SSGIHL KHIT
SSRIHLKRIT
TSQVRPRHIT

\section{MPF4 \\ RPF4 \\ HPF4}

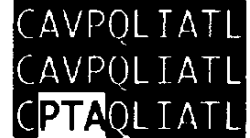

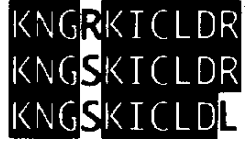

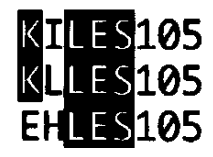

Fig. 2. Comparison of the predicted amino acid sequence of mouse $(M)$, rat $(R)$, and human $(H)$ PF4s

a defined sub-population of transcripts, it is a powerful and proven tool for identifying genes that are expressed differently among various tissues or cell lines (Ozaki et al.1996; Lim et al. 1997). In the study reported here we isolated a novel cDNA, the apparent murine homologue of rat and human platelet factor (PF)4, whose expression was significantly elevated in the NOA mouse.

\section{Materials and methods}

Differential display

Total RNA was extracted from the spleens of NOA and C57BL/6J mice with acid guanidine thiocyanate-phenolchloroform (Trizol reagent; Life Technologies, Rockville, MD, USA). From the total RNA, mRNA was isolated with Oligotex-dT30 (Japan Roche, Tokyo, Japan). cDNAs were synthesized with Superscript II reverse transcriptase (200 units; BRL, Gaithersburg, MD, USA) and 3'-anchored oligo (dT) primer g (T) 15MA (M represents a mixture of $\mathrm{G}, \mathrm{A}$, and $\mathrm{C}$ ).

The differential display method was performed as described previously (Ozaki et al.1996), except that the primer was labeled with ${ }^{33} \mathrm{P}$. Labeling was carried out as follows: $1 \mu \mathrm{l}$ of arbitrary primer was mixed with $3 \mathrm{ml}$ of ${ }^{33} \mathrm{P}$-dATP, $1 \mu \mathrm{l}$ of $10 \times$ kinase buffer (Toyobo, Tokyo, Japan), and $0.5 \mu$ l of poly-nucleotidekinase (Toyobo), in $4.5 \mu \mathrm{l}$ of distilled water, and incubated at $37 \mathrm{oC}$ for $30 \mathrm{~min}$. After ethanol precipitation the primer was dissolved in 5 $\mu \mathrm{l}$ of distilled water.

\section{Northern-blot analysis}

Northern blotting was performed using mRNAs isolated from the spleens of NOA mice and two control strains (C57BL/6J and BALB/c) at 8 and 30 weeks of age, since we considered that differences in immunologic response could occur with time. A $0.5-\mu \mathrm{g}$ aliquot of each poly (A) RNA was separated by electrophoresis on a $1 \%$ agarose gel containing $6 \%$ formalin, and transferred onto a charged-nylon membrane. Prehybridization and hybridization took place in a solution containing $50 \%$ formamide, $5 \times$ Denhardt's solution, $6 \times$ saline-sodium citrate solution (SSC), and $1 \%$ salmon sperm DNA. cDNA fragments that had been isolated in the differential display were labeled with ${ }^{32} \mathrm{P}-\mathrm{dCTP}$ by random-oligonucleotide priming. Membranes were washed twice for $20 \mathrm{~min}$ in $0.1 \times \mathrm{SSC} / 0.1 \%$ sodium dodecylsulfate (SDS) at $50^{\circ} \mathrm{C}$. Radioactivity was measured by means of a BAS 1000 Bioimage analyzer (Fujix, Tokyo, Japan)

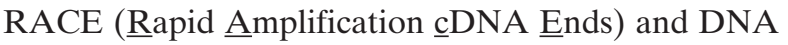
sequence

5' RACE experiments were performed essentially according to the supplier's recommendations (Marathon cDNA Amplification Kit, Clontech, Palo Alto, CA, USA). Amplified 5' cDNA fragments were subcloned into pT7BlueT (Novagen, Madison, NI, USA). Nucleotide sequences were determined with an ABI PRISM 377 DNA sequencer (Perkin-Elmer corporation, Norwalk, CT, USA). 


\section{Results}

To isolate novel genes associated with dysfunction of the immuno-regulatory system that may play crucial roles in the development of dermatitis in the NOA mouse, we used the differential display method to screen splenic mRNAs for genes that may be differently expressed in NOA and control mice. Using various primer sets, we identified a number of bands that indicated significantly higher or lower expression in the spleens of NOA mice. Northern-blot analysis using a PCR-amplified fragment corresponding to one such band confirmed that the expression level in the NOA mouse was higher than that in control strains (Fig. 1). Furthermore, in the NOA strain, expression of this gene was stronger in 30week-old mice than in 8-week-old mice, while in some controls its expression tended to decrease slightly with age.

To obtain a full-length cDNA of the unknown gene, we performed 5'RACE and obtained a total of 570 nucleotides containing 315 nucleotides of the open reading frame encoding 105 amino acids. Since the size of the transcript was estimated to be about $650 \mathrm{bp}$ on the basis of Northern analysis, we considered that the cDNA clone obtained from the RACE experiments covered almost the entire transcript. A homology search using the FASTA program (The Genome Net Database Service Japan (http://www.genome. ad.jp), revealed that the amino acid sequence predicted by this cDNA was $89 \%$ identical to rat PF4 and $64 \%$ identical to human PF4 (Fig. 2). This high degree of homology indicated that the gene isolated in these experiments was probably the murine homologue of rat and human PF4s. We termed this gene Pf4 (this gene will appear in the DDBJ/ EMBL/GenBank nucleotide sequence database with the accession number AB017491.)

Infiltration by eosinophils occurs in and around ulcerative lesions in atopic dermatitis. Therefore we also investigated the expression of two other chemokines, RANTES (regulated upon activation, normal $\mathrm{T}$ cell expressed and secreted) and eotaxin, which are thought to play important roles in eosinophilic infiltration (Doi et al. 1987; Poncz et al 1987). As shown in Fig. 3, the expression of eotaxin was significantly elevated in the 30-week old NOA mice compared with controls of the same age, although RANTES was not. Furthermore, as with $\mathrm{PF} 4$, eotaxin expression increased with age in the NOA mouse while it remained the same in the C57BL strain and decreased in the BALB strain at 30 weeks. The NOA mouse appeared to express RANTES more strongly than did the BALB strain, but not very differently from C57BL mice.

\section{Discussion}

Multiple genetic and environmental factors contribute to atopic dermatitis, the most common skin disease in western countries. Intensive investigations for genes underlying the etiology of this condition have been undertaken by a large number of groups worldwide; some reports indicate that FceRI $\beta$ on human chromosome 11 and interleukin 4 on chromosome 5 play roles in human atopic dermatitis (Cookson et al. 1992; Shirakawa et al. 1994; Marsh et al. 1994; Noguchi et al. 1997). However, since contradictory results have also been reported (Hizawa et al. 1992; Kofler et al. 1996), the genetic mechanisms involved remain unclear.

We chose the NOA mouse as an animal model because its pathological and serological features and scratching behavior closely resemble the manifestations of human atopic dermatitis (Kondo et al.1997). As this allergic condition is probably caused by dysfunction of the immunoregulatory system, we screened murine splenic mRNAs to detect genes that may be expressed differently in this tissue of NOA mice compared with control strains.

One gene we isolated by this approach appeared to be the murine homologue of human and rat PF4 genes (Broekman et al 1975; Kaplan et al 1979). PF4 belongs to the family of chemokines that contain a CXC motif, it is produced in megakaryocytes and packaged into $\alpha$-granules for release when platelets are activated (Ryo et al. 1983; Moore et al. 1975; Rucinski et al 1979). PF4 binds strongly to heparin, and neutralizes heparin-like molecules in the serum and on the surface of endothelial cells (Bruijinzeel et al 1993; Alam et al.1993). Moreover, in patients with atopic dermatitis, eosinophils show an elevated migratory response towards PF4 (Yamada et al.1996). PF4 may be a molecule that induces eosinophils toward the ulcerative skin lesions characteristic of this disease.

RANTES and eotaxin, two chemokines that contain the CC motif, are considered to play important roles in infiltration by eosinophils. RANTES may be related to local inflammation and allergy (Doi et al. 1987; Garcia-Zepeda et al. 1996), as its expression tends to be elevated in the skin and colon of patients with atopic dermatitis (GarciaZepeda et al. 1996). Eotaxin activates the migratory response of both eosinophils and basophils, and it is a specific chemo-attractant for eosinophils (Poncz et al 1987). Our Northern-blot analyses showed that PF4 and eotaxin were both expressed more strongly in the spleens of adult NOA mice than in younger mice, but expression levels of both

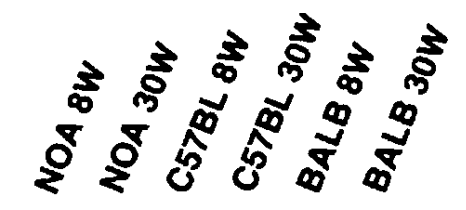

\section{RANTES}

Eotaxin

$\beta$-actin

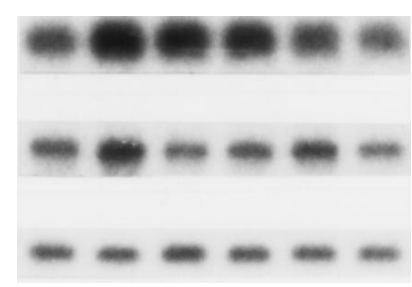

Fig. 3. Northern-blot analysis of regulated upon activation, normal Tcell expressed and selected (RANTES) and eotaxin in splenic tissues of NOA, C57BL/6J, and BALB/c mice at two different ages. Fragments obtained from differential display were amplified and used as probes. $\beta$-Actin expression served as a quantitative control. W, Weeks 
genes either decreased or were unchanged in the two control strains. Although RANTES expression in NOA mice was not stronger than in mice of the other control strains, of the same age, its expression in adult NOA mice was stronger than that in younger NOA mice. Ulcerative skin lesions develop in $30 \%$ of NOA mice by 10 weeks of age, and in $90 \%$ by 20 weeks (Kondo et al.1997). Hence, increased expression of some chemokines in the spleens of adult NOA mice may play a significant role in the development of atopic dermatitis. Since very little is known about the relationship between chemokines and atopic disorders, the findings reported here should be of value for investigating the etiology of allergic responses.

\section{Reference}

Alam R, Stafford S, Forsythe P, Harrison R, Faubion D, Lett- Brown MA, Grant JA (1993) RANTES is a chemotactic and activating factor for human eosinophils. J Immunol 150: 3442-3448

Broekman MJ, Handin RI, Cohen P (1975) Distribution of fibrinogen and platelet factor 4 and XIII in subcellular fractions of human platelets. Br J Haematol 31: 51-55

Bruijinzeel Pl, Kuijiper PH, Rihs S, Betz S, Warringa RA, Koenderman L (1993) Eosinophil migration in atopic dermatitis. Increased migratory response to $\mathrm{N}$-formyl-methionyl-leusil-phenylalanine, neutrophil-activating factor, platelet-activating factor, and platelet factor 4. J Invest Dermatol 100: 137-142

Coleman R, Trembath RC, Harper JI (1997). Genetic studies of atopy and atopic dermatitis. Br J Dermatol 136: 1-5

Cookson WO, Young RP, Sandford AJ, Moffatt MF, Shirakawa T, Sharp PA, Faux JA, Julier C, Nakumuura Y (1992) Maternal inheritance of atopic $\mathrm{IgE}$ responsiveness on chromosome 11q. Lancet 15: 381-384

Doi T, Greenberg SM, Rosenberg RD (1987) Structure of the rat platelet factor 4 gene: a marker for megakaryocyte differentiation. Mol Cell Biol 7: 898-904

Garcia-Zepeda EA, Rothenberg ME, Ownbey RT, Celestin J, Leder P, Luster AD (1996) Human eotaxin is a specific chemoattractant for eosinophil cells and provides a new mechanism to explain tissue eosinophilia. Nat Med 2: 449-456

Hanifin JM, Rajka G (1980) Diagnostic features of atopic dermatitis. Acta Dermao-Venereol Suppl 92: 44-47

Hizawa N, Yamaguchi E, Ohe M, Itoh A, Furuya K, Ohnuma N, Kawakami, Y (1992) Lack of linkage between atopy and locus 11q13. Clin Exp Allergy/ 22: 1065-1069
Kaplan Kl, Broekman MJ, Chernoff A, lesznik GR, and Drillings M (1979) Platelet $\alpha$-granule proteins. Studies on release and subcellular localization. Blood 53: 604-618

Kofler H, Aichberger S, Ott G, Casari A, Kofler R (1996) Lack of association between atopy and the Ile181Leu variant of the betasubunit of the high-affinity immunoglobulin E receptor. Int Arch Allergy Immunol 111: 44-47

Kondo T, Shiomoto Y, Kondo T, Kubo S (1997) The NOA mouse, a new hair-deficient mutant (A possible animal model of allergic dermatitis). Mouse Genome 95: 698-700

Liang P, Pardee AB (1992) Differential display of eukaryotic messenger RNA by means of the polymerase chain reaction. Science 257 : 967-971

Lim J, Kuroki T, Ozaki K, Kohsaki H, Yamori T, Tsuruo T, Nakamori S, Imaoka S, Endo M, Nakamura Y (1997) Isolation of murine and human homologues of the Fission-Yeast dis+ gene encoding a mitotic-control protein and its overexpression in cancer cells with progressive phenotype. Cancer Res 57: 921-925

Marsh DG, Neely JD, Breazeale DR, Ghosh B, Freidhoff LR, EhrlichKantzky E, Schon C, Krishnaswamy G, Beaty TH (1994) Linkage analysis of IL4 and other chromosome 5q31.1 markers and total serum immunoglobulin E concentrations. Science 264: 1152-1156

Moore S, Pepper DS, Cash JD (1975) Platelet antiheparin activity: The isolation and characterization of platelet factor 4 released from thrombin-aggregated washed human platelets and its disassociation into subunits and the isolation of membrane-bound antiheparin activity. Biochem Biophys Acta 379: 370-384

Noguchi E, Shibasaki M, Arinami T, Takeda K, Maki T, Miyamoto T,

Kawashima T, Kobayashi K, Hamaguchi H (1997) Evidence for linkage between asthma/atopy in childhood and chromosome 5q31-5q33 in a Japanese population. Am J Respir Crit Care Med 156: 1390-1393

Ozaki K, Kuroki T, Hayashi S, Nakamura Y (1996) Isolation of three testis-specific genes (TSA303, TSA806, TSA903) by a differential mRNA method. Genomics 36: 316-319

Poncz M, Surrey S, LaRocco P, Weiss MJ, Rappaport EF, Conway TM, Schwartz E (1987) Cloning and characterization of platelet factor 4 cDNA derived from a human erythroleukemic cell line. Blood 69: 219-223

Rucinski B, Niewiarowski S, James P, Walz DA, Budzynski AZ (1979) Anti-heparin proteins secreted by human platelets: Purification and characterization and radioimmunoassay. Blood 53: 47-62

Ryo R, Nakeff A, Huang SS, Ginsberg M, Deuel TF (1983) New synthesis of a platelet-specific protein: Platelet factor 4 synthesis in a megakaryocyte-rabbit bone marrow culture system. J Cell Biol 96: 515-520

Shirakawa T, Li A, Dubowitz M, Dekker JW, Shaw AE, Faux JA, Ra C, Cookson WO, Hopkin JM (1994) Association between atopy and variants of the $\beta$ subunit of the high-affinity immunoglobulin $\mathrm{E}$ receptor. Nat Genet 7: 125-130

Yamada H, Izutani R, Chihara J, Yudate T, Mtsukura M, Tezuka T (1996) RANTES mRNA expression in skin and colon of patients with atopic dermatitis. Int Arch Allerg Immunol 111: 19-21 